\title{
OBSERVATIONS IN LIDAR STATION OF ST. PETERSBURG STATE UNIVERSITY FOR ECOLOGICAL SAFETY STUDYIES
}

\author{
Vladislav Donchenko, Irina Melnikova, Dmitriy Samulenkov, Maksim Sapunov \\ St. Petersburg State University, Universitetskaya nab., 7/9, 199034, St. Petersburg, Russia, Email: \\ mikecf@mail.ru
}

\begin{abstract}
The solution of many problems associated with the air pollution, radiative regime of the earth's surface and atmosphere, global and local environmental changes and climate, facing humanity in the early 21 st century, require detailed and regular information on atmospheric aerosol and gaseous pollutants in the atmosphere. For monitoring atmospheric pollutants especially effective were the methods of laser sounding of the atmosphere, which provide a vertical profile of aerosol parameters to a height of $20 \mathrm{~km}$ In this regard, at the beginning of the $21 \mathrm{st}$ century created a continental networks of lidar sounding stations. Over Europe there is a network EARLINET. Laser station, built on the basis of St. Petersburg State University has become the first Russian station that acceded to the European research network. The article briefly presents the technical features of the equipment and demonstrates the first results of the observations.
\end{abstract}

\section{INTRODUCTION}

The creation of the Observatory of ecological safety of St. Petersburg state University was due to the need of research, creation of new techniques, the elaboration of advanced algorithms for regular monitoring of atmospheric pollution in the city with the use of high-tech lidar instruments [1]. Equipping the Observatory with laser systems provides environmental monitoring, the functioning of the laser station in the framework of the European laser network (EARLINET). In early 2014, the Station was associated in EARLINET, and now it is performing calibration and studying the accuracy of measurements and accomplishing observations according to the network schedule.

The Environmental Safety Observatory Resource Center of the St. Petersburg State University (SPbSU) located in the center of St. Petersburg on Vasilievsky Island, $10^{\text {th }}$ Line, $33 / 35$ at the roof of the university building: height of $35 \mathrm{~m}$, geographical coordinates: Lat $59.943 \mathrm{~N}$, Lon 30.273E. There is a mobile lidar complex mounted in a car for monitoring air quality around the city and suburbs. The main objectives of the SPbSU Observatory of Environmental Safety Resource Center are as follows [1]:

- Formation of models of the impact on the environment of potentially hazardous industries;

- Estimation of transboundary transport of atmospheric pollutants;

- Creation of forecast models of an unfavorable situation in the environment and approaches for the assessment of possible economic damage;

- Preparation of the synthesized maps of suspected areas and sites of threats to environmental and high ecological risk areas and sites;

Because the lidar station of the SPbSU Observatory of Environmental Safety Resource Center is now part of the European lidar network (EARLINET), the EARLINET networking enables the use of the information provided by lidar monitoring stations for modeling the transboundary pollution transport over Europe. At the same time, the data from atmospheric measurements presents an interest for solution of not only ecological problems but also of the problems of atmospheric physics and meteorology (the concentrations of trace gases, aerosol layers in the atmosphere).

Another important task accomplished by the SPbSU Resource Center is the development of training programs, including lecture courses and laboratory workshop to provide students with the skills they need to operate modern remote sensing facilities.

\section{METHODOLOGY}

Stationary and mobile multiwave lidar complexes provide information on the concentration and physical nature of atmospheric aerosol, chemical composition of the gas phase of the atmosphere, wind and turbulence at a distance of up to $25 \mathrm{~km}$ 
for vertical and slant paths in all directions. The lidar complex includes components and state of the art technology, available from both Russian and foreign manufacturers [2]. Aerosol lidar allows remote sensing in three elastic spectral channels: 355, 532, $1064 \mathrm{~nm}$ and Raman channels: $387,408,608 \mathrm{~nm}$. Polarization channel is at $355 \mathrm{~nm}$. Laser pulses of $\sim 10 \mathrm{nsec}$ duration, propagating in the atmosphere, interact with its various components and undergo partial backscattering to the gun. The backscattered signals from the pulse beam emitted by each laser into the atmosphere are collected by the same telescope and sent to the appropriate receiver. The signal is transmitted to the control computer, where it is processed in real time. The computer provides the processing of raw signal (background exposure accounting, smoothing over a group of pulses) [3]. Time scanning of the signal provides information on the points in space along the lidar beam propagation path.

The mobile complex is additionally equipped with a shortwave differential absorption lidar based on a tunable multiwave Ti:Sph laser operating in three wavelength ranges: $700 \ldots 960,350 \ldots 480$, 230...310 nm [2] for ozone, chlorine, oxides of nitrogen and sulfur indication in the atmosphere.

Further step consist in solving the inverse problem of lidar sensing, the retrieval of the concentrations of the substances detected. Special algorithms were developed for the solution of the entire set of inversions, which use different methods and approaches to the regularization of solutions for the different components monitored. The output appears as both the smoothed lidar backscattered signal and the quantities of polluting substances, in particular, against the corresponding threshold levels, and the direction and speed of their transport, i.e., in fact, one deals with the first stage of the inverse problem of environmental safety [1].

\section{RESULTS}

Figure 1 presents an example of the vertical profile of the volume extinction coefficient $\alpha(z)$ in the height $(\mathrm{m})$ - time (hour) coordinates, derived from 532- and 355-nm channel measurements in the zenith direction on March 5, 2015, during 2.5 hours. A "pollution cap" above the city up to the height of $1.0 \mathrm{~km}$ can be clearly seen in the figure. Another characteristic of aerosol particles is their
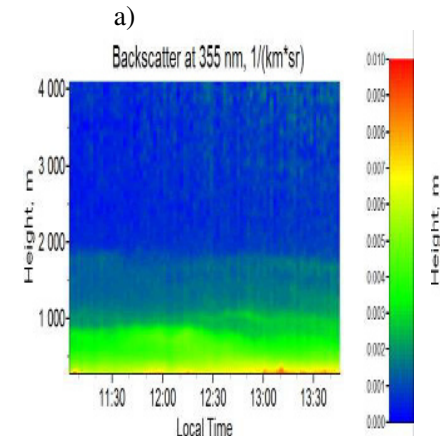

b)

Fig.1. Dynamics of vertical profiles of a) backscattering coefficient at $532 \mathrm{~nm}$ and b) particle depolarization from observation 5 March 2015

shape. Typically, spherical (or nearly spherical) and non-spherical (crystals, chains, etc.) particles are distinguished. The shape of the particles is determined by their origin and may indicate the source of aerosols. Figure $1 \mathrm{~b}$ demonstrates the particle depolarization for the same time. It is seen that there is a lot of dust not spherical shape in the lower layer.

Figure 2 shows the profile of the atmospheric aerosols concentration.

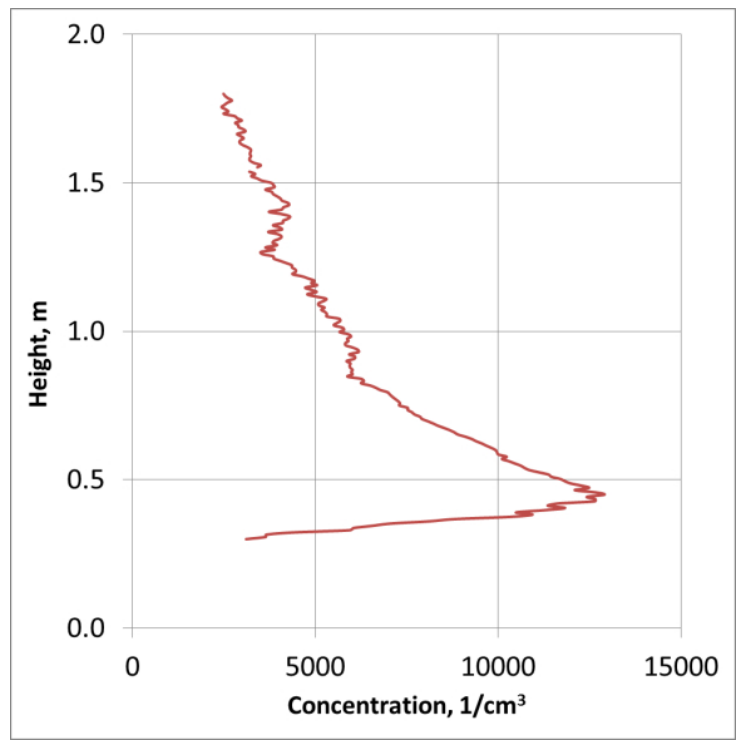

Fig.2. Vertical profiles of particle concentratione index from observation 5 March, 2015

The peak of $120001 / \mathrm{cm}^{3}$ at the height $0.5 \mathrm{~km}$ is clear distinguished.

There are profiles of real and imagine parts of the refractive index on the Fig.3 those are not varied significantly and pointed to dust component in the height ranges $0.3-2 \mathrm{~km}$. 
a)

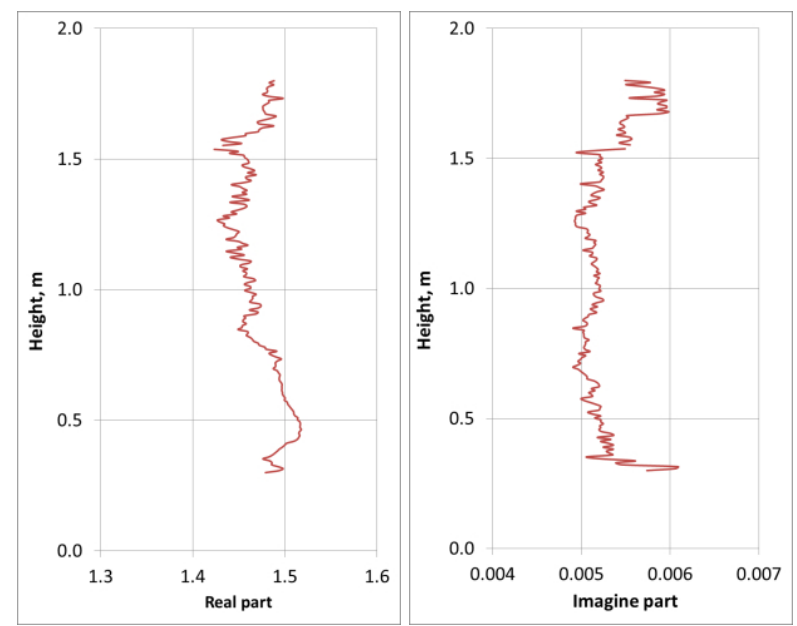

Fig.3. Vertical profiles of a) real part of refractive index, b) imagine part of refractive index from observation 5 March, 2015

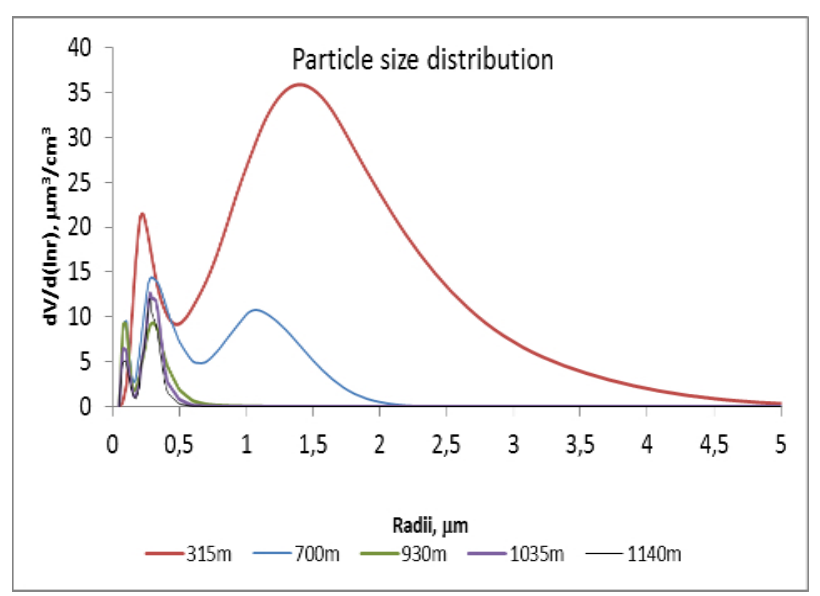

Fig.4. Particle size distributions at 5 altitudes, pointed in figure a)

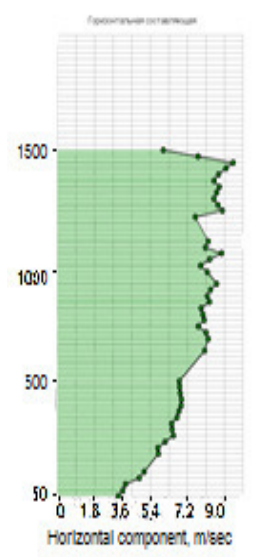

b)

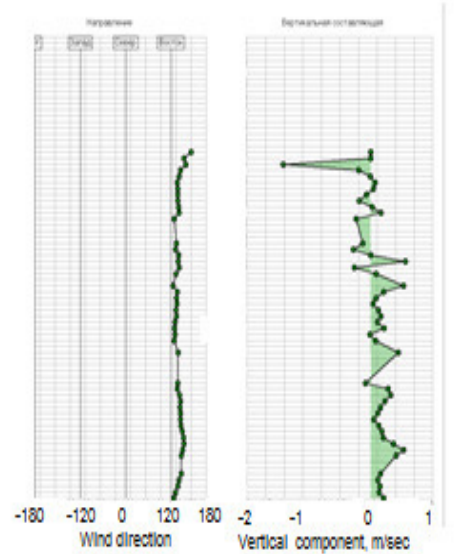

Fig.5. Vertical profiles of the horizontal and vertical velocity and wind direction from observation 5 March, 2015. a) horizontal component, b) - direction and c) vertical component (positive values correspond to upward motions).
The Fig. 4 demonstrates the particle size distribution at 5 altitudes 315 (red line), 700 (blue line), 930 (green line), 1035 (violet line) and $1140 \mathrm{~m}$ (black line). It is clearly seen the transformation particle sizes with height: larger particle are in lower heights, and very small particles are higher $1 \mathrm{~km}$.

The wind Doppler lidar [4] provides registration of the vertical profile of horizontal and vertical components of the wind velocity and the wind direction that are demonstrated in the Fig. 5. Fig 5 a corresponds to horizontal wind velocity, $5 b-$ to wind direction, and $5 \mathrm{c}-$ to vertical velocity component. The positive values point to upward air motion. It is detectable the wind shift at height $1.4 \mathrm{~km}$ and the downward motion at the same height. The zeroth vertical velocity at the height $0.5 \mathrm{~km}$ might explain the particle concentration peak.

\section{ATMOSPHERIC POLLUTION IMPACT ON THE PUBLIC HELTH}

As it was mentioned in [5, 6] the role of air pollutants in triggering asthma exacerbations in young and adult asthma patients is established. Several studies [7, 8] support the role of air pollution in the development of asthma in childhood. According to [9] long-term exposure to particulate air pollution $\left(\mathrm{PM}_{10}\right)$ was associated with nonaccidental mortality, mortality from respiratory diseases, and lung cancer mortality in our study population of 7 million adults. Furthermore, $\mathrm{PM}_{10}$ was associated with cardiovascular mortality. These points demonstrate importance of monitoring air conditions under big city conditions. The lidar instruments are very suitable for this purpose.

\section{CONCLUSION}

Studying atmospheric pollution with the use of stationary lidar complex in big cities, like, the case study of St. Petersburg, provides insight into the spatial distribution and temporal dynamics of the air pollution in a city. The obtained characteristics can be represented as the risks of high level of air pollution, whose impact on the health of the population can be assessed. The situational-information center could accomplish processing of the monitoring data in real time or operatively and forecast the ecological situation 
dynamics. Hence, the active optical methods of ground-based atmosphere remote sensing allow determining not only optical parameters of the atmosphere and atmospheric aerosols but also the environmental parameters: environmental risks of hazardous events associated with the condition of the atmosphere on the local scale.

The activities undertaken by the St. Petersburg State University Resource Center in the frames of the European network are aimed at effective exchange of data, algorithms and methods of data processing, which is currently in progress.

\section{ACKNOWLEDGEMENT}

State contract RF number 16.740.11.0619 of 31.05.2011 "Development of methods for studying the physical processes of the formation of atmospheric pollution by smoke and smog"

Agreement No. 14.B37.21.1528 from 01.10.2012 "Modeling of the formation and dynamics fields of atmospheric aerosol, formed as a result of forest fires, for operational forecasting of the atmosphere and study of regional climate"

Agreement No. 14.574.21.0088 from the 16.07.2014 (topic: Conducting applied research on the development of an automated information system for monitoring and forecasting the balance for urban storm water drainage systems") in the framework of realization of the Federal target program "Research and development on priority directions of development of scientifictechnological complex of Russia for 2014 - 2020" (a Unique identifier for applied scientific research (project) RFMEFI57414X0088).

\section{REFERENCES}

[1] Melnikova I., Donchenko V., Boreisho A., Morozov A. 2010: Laser Complexes for the Solution of the Inverse Problem of Ecological Monitoring, Proceedings of the 25th International Laser Radar Conference, 2010. 131-133

[2] Boreysho A.S., Chakchir S.Ya., Konyaev M.A., Konovalov K.A., Savin A.V. 2005: Optical Heterodyning in Differential Tunable CO2 Laser Systems. American Institute of Aeronautics and Astronautics, Toronto, Chapter DOI:

$10.2514 / 6.2005-5367$

[3] Veselovskii I., Whiteman D.N., Kolgotin A., Andrews E., Korenskii M. 2009: Demonstration of aerosol property profiling by multi-wavelength lidar under varying relative humidity conditions J. Atmos. Ocean Tech. 26, 1543-1557.

[4] Akhmetianov B.R., Vasilyev D.N., Konyaev M.A., Mishina O.A., Penkin M.S., Petrov G.A., Tezadov Ya.A., Shatalov I.V., Shiryaev I.F. 2013: Approaches and algorithms for data processing of wind coherent Doppler lidar with cone scanning. The Journal of radio electronics, No. 10, 11-23

[5] Peel JL, Tolbert PE, Klein M, Metzger KB, Flanders WD, Todd K, et al. 2005. Ambient air pollution and respiratory emergency department visits. Epidemiology 16:164-174.

[6] Sunyer J, Spix C, Quenel P, Ponce-de-Leon A, Ponka A, Barumandzadeh T, et al. 1997. Urban air pollution and emergency admissions for asthma in four european cities: The APHEA project. Thorax 52:760-765

[7] Anderson HR, Favarato G, Atkinson RW. 2013 Long-term exposure to air pollution and the incidence of asthma: meta-analysis of cohort studies. Air Qual Atmos Health 6:47-56.

[8] McConnell R, Islam T, Shankardass K, Jerrett M, Lurmann F, Gilliland F, et al. 2010. Childhood incident asthma and traffic-related air pollution at home and school. Environ Health Perspect 118:1021-1026.

[9] Fischer Paul H., Marra Marten, Ameling Caroline B., Hoek Gerard, Beelen Rob, Kees de Hoogh, Breugelmans Oscar, Kruize Hanneke, Janssen Nicole A.H., Houthuijs Danny. Air Pollution and Mortality in Seven Million Adults: The Dutch Environmental Longitudinal Study (DUELS). Environ Health Perspect. Advance Publication: 11 March 2015. 